\title{
LA POLITICA EDUCATIVA Y EL CAMBIO SOCIAL DEL REGIMEN CONSERVADOR A LA REPUBLICA LIBERAL
}

(1903 - 1930)

Alfredo Molano B. ${ }^{*}$

César A. Vera G.*

La escuela, esa imagen

en pequeño de la sociedad

H. de Balzac

\section{INTRODUCCION}

El ensayo que se presenta a continuación corresponde a un capítulo del primer volumen de la investigación: "Evolución de la política educativa durante el siglo XX", próximo a publicarse.

Tomando como punto de partida la Ley 39 de 1903 denominada también "Reforma Uribe" se describe y analiza el comportamiento de la política económica del Estado, haciendo énfasis en el período conocido como la "danza de los millones" y la crisis del año 1930, y estableciendo la relación de estos procesos con la política educativa oficial. Es importante destacar que a través del análisis se hacen alusiones muy tangenciales a las administraciones presidenciales de José Vicente Concha 1914-1918 y Marco Fidel Suárez 1918-1922, pues en estos años las reformas educativas y socio -económicas fueron particularmente lánguidas.

El lector tendrá oportunidad de analizar cómo la ingente inversión extranjera y la creación de una infraestructura industrial durante el gobierno del general Pedro Nel Ospina 1922-1926, dieron origen al surgimiento de tendencias pedagógicas innovadoras como el célebre proyecto de la "Escuela Nueva" acaudillado por don Agustín Nieto Caballero y la obtención de la carta de ciudadanía del movimiento estudiantil universitario, factor que gravitó grandemente en la caída del régimen conservador.

\section{La política educativa del régimen conservador}

\section{A. La reforma Uribe}

El punto de partida de toda la legislación escolar en lo que va corrido del presente siglo ha sido la Ley 39 de 1903, llamada también Ley Orgánica, inspirada por don Antonio José Uribe, norma que fue reglamentada al año siguiente por medio del Decreto 491 de 1904. Se constituyó así la legislación educativa básica del período que fue, por lo demás, singularmente discreto en modificaciones posteriores. En efecto, las normas durante los 30 primeros años del siglo, si se omite la Ley Orgánica y la Ley 56 de 1927, se reducen a la prohibición de la férula y de los castigos infamantes en 1911; a la asignación de

\footnotetext{
* Sociólogo Universidad Nacional. Estudios de postgrado en la Escuela Práctica de Altos Estudios de París. Investigador del Centro de Investigaciones de la Universidad Pedagógica Nacional.

${ }^{* *}$ Licenciado en Historia Universidad del Rosado. Investigador del centro de Investigaciones de la Universidad Pedagógica Nacional.
} 
pensiones de jubilación para maestros en 1913; a la organización del Congreso Pedagógico en 1919 y a la organización de las fiestas de la madre, la bandera y el ahorro en 1925.

La Ley Orgánica de Instrucción Pública es considerada el fundamento jurídico del sistema educativo colombiano durante la primera mitad del siglo, por cuanto las disposiciones posteriores no cambiaron esencialmente su estructura ${ }^{82}$.

La Ley de 1903 subordina definitivamente la educación a la doctrina de la Religión Católica y al Estado tal como lo estipulaban la Constitución de 1886 y el Concordato, y divide la instrucción pública en primaria, secundaria, industrial y profesional. La primera sería gratuita pero no obligatoria, y costeada y regida por los departamentos; la segunda estaría a cargo de la Nación e inspeccionada por el poder ejecutivo, y la tercera debería ser financiada también por la Nación y por los departamentos.

La instrucción primaria queda definida como "esencialmente práctica" y orientada a dotar al alumno de las "nociones elementales que lo habiliten para el ejercicio de la ciudadanía y lo preparen para el de la agricultura, la industria y el comercio"83. La secundaria fue a su vez especializada en técnica (cultura general, idiomas, materias profesionales) y clásica (filosofía y letras) aunque se recomienda fomentar prioritariamente la instrucción técnica. La entidad encargada de la enseñanza industrial y comercial, se debía preocupar por la fundación de escuelas de artes y oficios donde se adiestrarían los estudiantes en la manufactura y "en el manejo de máquinas aplicables a las pequeñas industrias" ${ }^{84}$. Por último la instrucción profesional sería dada por la Facultad de Filosofía y Letras del Colegio Mayor del Rosario, a la cual se le reconoce autonomía, por las Facultades de Medicina, Ingeniería, Derecho, por la Escuela de Veterinaria y el Colegio Dental, institutos todos regidos por un Consejo Directivo nombrado anualmente por el gobierno. Se crea igualmente el Consejo Universitario como cuerpo consultivo nombrado por el Presidente de la República.

El Decreto 491 de 1904, se brindaba en el Artículo 40 de la Ley 39 de 1903, que estipulaba que cualquier perfeccionamiento posterior de la norma debería "descansar sobre la triple base de la educación normal y religiosa en todos los estudios; de la educación industrial en la primaria y la secundaria; y de los estudios profundos, severos y prácticos en la instrucción profesional" ${ }^{85}$. El decreto legisló en forma precisa y casuística sobre múltiples aspectos del sistema educativo: las atribuciones del ministro del ramo, de los secretarios de instrucción pública y del Consejo Universitario; las modalidades de la inspección y organización de la enseñanza primaria, secundaria y profesional, etc. Fue particularmente minucioso en lo referente a la escuela elemental, que clasificó en rural y urbana y precisó diversos tópicos tales como la catequización de indígenas, el sostenimiento de las escuelas, el número de niños permisibles en cada una de ellas, la edad escolar y el plan de estudios. Según el decreto la enseñanza primaria debía integrar la educación moral, cuyo fin "es la práctica de los deberes para con Dios, para consigo mismo, para con los padres y superiores, para con los semejantes y para con la patria"; con la educación intelectual, "que desarrolla en el niño el conjunto de facultades mentales"; y con la educación cívica y física ${ }^{86}$. Basado en estas orientaciones, el estatuto

\footnotetext{
${ }^{82}$ lvon Lebot. Educación e Ideología en Colombia. Editorial La Carreta. Medellín, 1975 p. 17.

${ }^{83}$ Mineducación. Educación Colombiana 1903-1958. Imprenta Nacional, Bogotá. 1959 p. 9.

${ }^{84}$ Ibídem p. 10.

${ }^{85}$ Ibídem p. 13.

${ }^{86}$ Ibídem p. 26.
} 
definió el plan de estudios de la primaria diferenciando la escuela rural de la urbana, el pénsum para niños y para niñas, y las materias para cada nivel. La escuela rural constaría en adelante de un ciclo de tres años, alternado según sexo, y la urbana por uno de seis años dividido en tres niveles, elemental, medio y superior. Las diferencias curriculares entre la escuela rural y urbana pueden ser ilustradas en las asignaturas estipuladas para el primer año: en la rural, el niño aprendía religión, lectura y escritura, aritmética y urbanidad; en la urbana, a las anteriores materias se agregaban dibujo lineal, canto, lecciones objetivas, "calistenia" y "obras de mano".

El decreto legisló también sobre los textos. Estableció que éstos debían ser aprobados por una junta de pedagogos y por el Arzobispo de Bogotá; sobre la calidad y deberes de los maestros; sobre la matrícula y asistencia, y sobre los exámenes y el sistema correccional.

En relación con la instrucción secundaria, la reglamentación de 1904 fue menos amplia, e hizo referencia básicamente a los planes de estudio de las escuelas normales, de la instrucción técnica y de la clásica, así como a la fundación de la Revista de Instrucción Pública. Las escuelas normales tenían como objeto la formación de maestros de primaria y deberían existir en cada departamento, siendo la Escuela Normal de Cundinamarca la encargada de formar el personal docente para todas las otras normales. El conjunto de materias del plan estaba orientado "a la adquisición de nociones suficientes no sólo en el orden moral e intelectual sino también en los principios aplicables a la industria, la agricultura y el comercio"87 La instrucción técnica comprendía materias preferencialmente vinculadas con las ciencias naturales y con las matemáticas y guiadas por el "método empírico". La secundaria clásica por el contrario, poseía una orientación más teórica y especulativa.

Vista en su conjunto la reforma fue una expresión directa de los fundamentos constitucionales formulados por Núñez y Caro, donde predominan tres elementos: la unidad nacional, la preeminencia de la Religión Católica, y el "fomento de la riqueza".

Ciertamente la Reforma Uribe tenía el antecedente inmediato del Plan Zerda de 1892, que inspirado también en la reforma del 86 y en el Concordato, pretendió unificar el sistema educativo, dotar al Estado de instrumentos que hicieran viable la "Suprema inspección y reglamentación de la enseñanza", tal como lo ordenaba el Artículo 41 de la Constitución, y dar cumplimiento a los artículos 12 y 13 del Concordato que supeditaban la organización de la educación pública a la Iglesia. Pero Uribe fue más allá al lograr una mayor organicidad del plan anterior ${ }^{88}$ y sobre todo, al deducir la ley del proyecto hegemónico que el conservatismo había formulado como consecuencia del triunfo en la Guerra de los Mil días ${ }^{89}$. Después de la guerra, la unidad nacional que los constituyentes del 86 habían buscado por medio de la centralización política, y del intervencionismo se hacía no sólo necesaria, sino posible con la derrota del liberalismo. Unidad, centralización e intervencionismo eran los ejes sobre los cuales giraba el proyecto político conservador.

La unificación de la Nación y del Estado no dependía solamente de la centralización política. Era también un problema de unidad espiritual e ideológica. La Iglesia Católica como poder real, centralizado y jerarquizado y como doctrina ideológica unitaria, profundamente arraigada en el pueblo colombiano, se constituía en uno de los

\footnotetext{
${ }^{87}$ Ibídem p. 27.

${ }^{88}$ Jaime Jaramillo Uribe. El proceso de la educación. Manual de Historia de Colombia. Tomo III. Colcultura, Bogotá, 1980 p. 280.

${ }^{89}$ Cfr. Jorge O. Melo. La República Conservadora en: "Colombia Hoy”. Editorial Siglo XXI, Bogotá, 1978 p. 35.
} 
fundamentos principales de esa unidad. En estos términos el Concordato fue el complemento necesario de la Constitución del 86. La unidad doctrinaria del catolicismo y su trayectoria como basamento cultural de la Nación; la amplitud y solidez del aparato burocrático de la Iglesia y la legitimidad y aceptación de su autoridad eran elementos indispensables para el proyecto político conservador. En esta perspectiva, la educación, "organizada y dirigida de conformidad con los dogmas y la moral de la Religión Católica", cobraba todo su significado. Para la unidad política era necesaria la unidad ideológica y para ello, la Iglesia garantizaba la orientación católica de la educación y aportaba su aparato institucional, su organización, su estructura. Fue así como el conjunto de las funciones asignadas a la Iglesia tomaron cuerpo en los artículos 12 y 13 del Concordato.

Pero el Estado no podía endosar, sin nefastas consecuencias para el ejercicio de su autoridad, toda la responsabilidad educativa en la Iglesia. Así se explican los artículos de la Constitución relativos a la suprema inspección de la educación y a su sostenimiento por parte del gobierno y la Nación que tanto el Plan Zerda como la Reforma Uribe reservaron al Estado. De otro lado, la Ley Orgánica avanza un paso más sobre la legislación anterior mediante la reorganización del Ministerio de Instrucción Pública, lo cual implicó una definición rigurosa de las funciones directivas y administrativas del ejecutivo ${ }^{90}$.

El papel asumido por el Estado en la educación pública era expresión de la tendencia hacia la centralización, tendencia que fue todavía más nítida en la promulgación de un Plan Nacional de Estudios para la primaria y la secundaria, y en la homogenización legal de principios pedagógicos relativos al sistema correccional y a las funciones de los exámenes y de los maestros ${ }^{91}$.

De esta manera la reforma de Uribe puede ser vista como un esfuerzo para utilizar la educación como un medio para lograr la unidad ideológica de la Nación y afianzar, por este camino, la presencia del poder central en la vida nacional.

Ahora bien, la Ley Orgánica no contempló la educación solamente como una palanca, por lo demás formidable para estimular la unificación espiritual de la Nación y forzar la centralización del poder, sino que también le señaló un papel sobresaliente en el campo de la economía.

En efecto, en las últimas décadas del siglo XIX, específicamente a partir de la guerra de 1876, el país comenzó a dar con escasos éxitos pero con halagadoras perspectivas, los primeros pasos en la industrialización ${ }^{92}$. El desarrollo de la minería sobre bases técnicas estimuló el surgimiento de pequeñas fábricas que generaban mercados urbanos; el crecimiento de la banca y de la acumulación de capital comercial, complementaban el esfuerzo al atender solícitamente los requerimientos del capital productivo. El triunfo de Núñez y de la política proteccionista alimentaron la esperanza de los empresarios fabriles, y a pesar de la ambigüedad de las medidas económicas tomadas por la Regeneración y de la inestabilidad política, fue "posible advertir que... a partir de 1890 aumenta el interés por el establecimiento de industrias modernas sobre todo en Antioquia"93 Por otro lado, la economía cafetera venía desarrollándose lenta pero constantemente desde 1870 . Entre 1887 y 1897 se sembraron cerca de 30 millones de árboles solamente en la zona oriental, y se incrementaron las exportaciones de café a una tasa promedio del 18.5 por ciento ${ }^{94}$, la

\footnotetext{
${ }^{90}$ Artículos 1 al 5 de la Ley 39 de 1903 y Capítulo 1 del Decreto 491 de 1904. Educación Colombiana p. 17 y ss.

${ }^{91}$ Ibídem. Decreto 491 capítulos IX, XI y XII.

${ }^{92}$ Jorge O. Melo. La evolución económica de Colombia 1830-1900. Manual de Historia de Colombia. Tomo III. Colcultura, Bogotá, 1978 p. 204.

${ }^{93}$ Ibídem. p. 204.

${ }^{94}$ Absalón Machado. El café: De la aparcería al capitalismo. Editorial Punta de Lanza. Bogotá, 1977. p. 33. 
exportación pasó de 106.431 a 510.179 sacos. Para 1885-90 los ingresos provenientes de este renglón generaron cuatro millones de pesos, casi el doble de lo que representó el tabaco en su mejor época (de 1866 a 1869) ${ }^{95}$.

En estos términos, al finalizar el siglo XIX la economía del país exhibía síntomas alentadores de un crecimiento fundado sobre bases sólidas y con perspectivas nuevas, que no lograron demoler ni oscurecer la sucesión de guerras civiles ocurridas en las tres últimas décadas de ese siglo.

El propósito de contribuir por medio de la educación a enfatizar la tendencia de desarrollo, estimular el crecimiento de la economía y recuperar el ritmo perdido con ocasión de la Guerra de los Mil Días, está claramente expuesto en la reforma de Uribe. Aparecen en primer lugar dos innovaciones frente al plan Zerda: la diferencia, aunque todavía vaga, entre la instrucción profesional y la instrucción industrial, y la división de la secundaria en técnica y clásica. La distinción entre lo técnico y lo clásico, entre lo industrial y lo profesional, y la concordancia entre lo técnico y lo industrial, lo clásico y lo profesional apuntan, sin lugar a dudas, a esbozar un programa de educación técnica divorciado del esquema tradicional heredado de la Colonia. En segundo lugar, el estatuto de Uribe subraya de manera persistente los objetivos económicos de la educación aunque sin detrimento de los objetivos morales. La enseñanza debía habilitar a los educandos para el ejercicio de la ciudadanía, de la agricultura, de la industria fabril y del comercio ${ }^{96}$. Las escuelas normales debían formar maestros idóneos para transmitir a sus alumnos nociones suficientes no sólo en el orden moral e intelectual, sino también principios aplicables en la industria, la agricultura y el comercio ${ }^{97}$. Por medio del Artículo 16 de la Ley de 1903, las Asambleas Departamentales quedaron facultadas para establecer "escuelas de artes y oficios que enseñen artes manufactureras y especialmente el manejo de máquinas aplicables a las pequeñas industrias"98 - El Instituto Agrícola y la Escuela de Minas atenderían de "un modo científico la explotación de las riquezas naturales del país"

En estos términos, la reforma de Uribe le atribuyó a la educación y también al sistema educativo una responsabilidad económica. Pero sobre todo, se destaca el propósito explícito de calificar técnicamente a todos los niveles la mano de obra que requería el desarrollo industrial. Quizás por este motivo la Ley Orgánica privilegió tan unilateralmente la escuela primaria urbana. Para los gobiernos conservadores posteriores a la Guerra de los Mil Días, la posibilidad de la industrialización se transformé en una opcién real e inmediata. La reforma de Uribe, en este sentido, no fue más que la expresíón de esa alternativa; la habilitación práctica de la fuerza de trabajo en el menor tiempo posible era el reto que debía afrontarse. "La clase empresarial y la burguesía nacional - -dice Jaramillo Uribe--- que siempre habla manifestado sus exigencias de una educación más práctica, adecuada a los nuevos proyectos económicos, siguió insistiendo en ellos bajo los gobiernos posteriores a la guerra. Desde el punto de vista legislativo, la Ley Organica... respondió a esa exigencia" ${ }^{100}$.

\footnotetext{
${ }^{95}$ Salomón Kalmanovitz. El régimen agrario durante el siglo XIX. Manual de Historia de Colombia. Tomo II. Colcultura, Bogotá, 1978. p. 307.

${ }^{96}$ Ley 39 de 1903, artículo 6o. Educación colombiana. p. 22.

${ }^{97}$ Ibídem. Art. 15.

${ }^{98}$ Ibídem. Art. 16.

${ }^{99}$ lyon Lebot. Op. cit. p. 22.

100 Jaime Jaramillo U. Qp. cit. p. 281.
} 


\section{B. Del Quinquenio a la danza de los millones}

Al finalizar la primera década del nuevo siglo, el país se recuperaba política y económicamente de la Guerra de los Mil Días. El gobierno autoritario del general Reyes (1904-1910), Ilamado usualmente El Quinquenio, sorteó habilidosamente los obstáculos que le interponían las aspiraciones hegemónicas del conservatismo en pugna con las demandas de reconocimiento al derecho de minorías que reclamaba el liberalismo. El resultado de esa tensión fue un período de relativa estabilidad política que consolidó al régimen. Bajo el lema de "Menos política y más administración", Reyes puso en marcha un plan de saneamiento de las finanzas públicas, fortaleció el presupuesto, organizó el banco Central para controlar la emisión, y racionalizó la deuda pública. Ello permitió acometer un importante plan de obras públicas que estimuló el desarrollo de la industria, y que fue complementado mediante la acentuación del proteccionismo y la defensa de las garantías a los empresarios industriales.

"El proteccionismo de Reyes —dice Ospina Vásquez- llevaba al plano de la eficacia el proteccionismo esbozado por Núñez"101. Durante "El Quinquenio" se inició la refinación de petróleo; se multiplicó la manufactura del ácido sulfúrico, del vidrio, del papel, del jabón, de los fósforos y de la cerveza. Se fundaron nuevos ingenios azucareros y se acentuó el ritmo de crecimiento en la industria textil. En relación con la industria existente antes de la Guerra de los Mil Días - dice Bejarano- la nueva industria "es cuantitativamente superior... y tiene una tecnología favorablemente modernizada"102. Por su lado, la economía cafetera experimentó en el primer decenio un impulso notorio. Nuevas zonas son integradas a la producción, particularmente en Antioquia y Caldas y las técnicas de cultivo y de comercialización hacen grandes avances; todo lo cual se refleja en el hecho de que "a partir de 1905 el café logra un crecimiento relativamente continuo que dura hasta $1930^{103}$.

Los éxitos alcanzados por la política económica de Reyes y el control autoritario logrado sobre las veleidades de una oposición sin banderas, se expresaron en un período de sólida estabilidad institucional y en una evidencia irrebatible de la eficacia del sistema político ideado por Núñez y Caro.

La primera Guerra Mundial (1914-1918) indujo en la economía un receso ambiguo y relativo. La exportación de café no sólo no se vio afectada sino que se incrementó. En 1912 el país exportó unos 900.000 sacos y en 1919 dobló esta cifra; el valor de las exportaciones del grano se triplicaron y pasaron de 18.6 millones de dólares a 58.5 millones $^{104}$. Sin embargo, las dificultades de importación creadas por la guerra afectaron, en un primer momento, el pulso de la industria, pero luego, esas mismas dificultades se convirtieron en una barrera protectora que impulsó nuevamente la producción industrial ${ }^{105}$. De esta manera, dice Bejarano, "la primera Guerra Mundial haría ver cómo los contratiempos creados por ella en el comercio exterior se revelaban, si se veían positivamente, como la oportunidad de avanzar en la industrialización nacional sobre las bases creadas por el desarrollo cafetero"106.

\footnotetext{
${ }^{101}$ Luis Ospina Vásquez. Industria y protección en Colombia 1810-1930. Medellín. Editorial Santa Fe, 1955. p. 325.

102 Jesús A. Bejarano. La economía en el siglo XX. Manual de Historia de Colombia. Tomo III. Colcultura, Bogotá, 1980 p. 23.

${ }^{103}$ Jorge O. Melo. La República Conservadora. Op. cit. p. 77.

${ }^{104}$ Ibidem p. 77.

${ }^{105}$ Cfr. Ospina Vásquez. Op. cit. p. 365 y Rafael Poveda Ramos. Historia de la industria en Colombia. Revista trimestral de la ANDI No. 11. Medellín. 1970 p. 35.

${ }^{106}$ Bejarano. Op. cit. p. 32.
} 
Ahora bien, el cauteloso pero significativo desarrollo de las obras públicas, fundamentalmente en ferrocarriles, cuya red pasó de 200 kilómetros a principios de siglo a 900 en $1910^{107}$; el fortalecimiento del sector fabril, que en 1916 contaba con 13 fábricas en Bogotá, 25 en Antioquia, 10 en Atlántico y 8 en Bolívar ${ }^{108}$; el crecimiento de las exportaciones ,que aumentó entre 1910 y 1919 a una tasa promedio anual del $11 \%{ }^{109}$, se constituyeron en los resortes de un doble fenómeno que comenzó a afectar sensiblemente el perfil social del país: la urbanización y la emergencia de la clase obrera. Hacia mediados de la segunda década Bogotá tenía 120.000 habitantes, cifra que representaba el $17 \%$ de la población departamental; Barranquilla concentraba 50.000 habitantes, o sea el $43 \%$ de la población del departamento; Medellín concentraba 70.000 almas y Cali 50.000 , lo que equivale a decir que un $12 \%$ de la población total era urbana ${ }^{110}$. Paralelamente a este conjunto de transformaciones va surgiendo la clase obrera y la manifestación más palpable de su existencia: desde 1910 se comienza a sentir su agitación, en 1913 se establece fugazmente la Unión Obrera de Colombia; en 1918 se declaran en paro los trabajadores portuarios de la Costa Atlántica, y en 1919 se reúne un congreso obrero, ano en que es reconocido legalmente el derecho de huelga y en el que se funda el Partido Socialista. De 1909 a 1920 se otorgan 30 personerías jurídicas a diferentes asociaciones obreras ${ }^{111}$.

Así, al finalizar la primera Guerra Mundial, la estructura social y económica del país tiende a modificarse notablemente. Una nueva clase empresarial ligada a la industria manufacturera nacional va adquiriendo personalidad económica; los comerciantes vinculados al sector exterior ven consolidar con optimismo la economía cafetera y la clase obrera irrumpe tímidamente en el escenario nacional. El terrateniente, el aparcero, el artesano, el comerciante rutinario se dan cuenta de golpe que no son los únicos personajes, que han surgido nuevos protagonistas, nuevos intereses, nuevas ideas, nuevas fuerzas. La sociedad colombiana se halla a la puerta de un trascendental movimiento social que modificará sustancialmente su arquitectura y sacudirá fuertemente sus cimientos.

Las transformaciones, sus ecos y sus signos, no lograron sin embargo, dejar huella ni su inquietud en el sistema educativo. De 1904 a 1920 la política educativa del Estado se mantiene invariable. El estatuto de Antonio José Uribe mostraba versatilidad y eficacia para responder a las demandas del sistema pero también una manifiesta incapacidad para adaptarse al ritmo de los cambios y sobre todo para albergar las tendencias y las perspectivas que se esbozaban. Mientras en Antioquia se montan miles de telares y de husos modernos ${ }^{112}$, el Ministro de Instrucción, ajeno a la novedad, tan sólo prohíbe la férula ${ }^{113}$ mientras el país se ve abocado a las vicisitudes que trae la primera Guerra Mundial, Carlos E. Restrepo firma un decreto reconociendo a los maestros el derecho a la jubilación ${ }^{114}$, mientras la clase obrera tiende hacia su organización, el presidente Concha firma la Ley 62 de 1916, por la cual se fomentan algunas corporaciones pedagógicas ${ }^{115}$. Nada sustancial, nada que permitiera prever las grandes tensiones y los grandes desafíos que enfrentaría el sistema educativo en los años inmediatamente venideros.

\footnotetext{
${ }^{107}$ Melo. Op. cit. p. 81.

${ }^{108}$ Bejarano. Op. cit. p. 23.

${ }^{109}$ Melo. Op. cit. p. 86.

110 Bejarano. Op. cit. p. 86.

${ }^{111}$ Miguel Urrutia. El desarrollo del movimiento sindical y la situación de la clase obrera. Manual de Historia de Colombia. Tomo III. Colcultura, Bogotá, 1980 p. 236.

112 Ospina Vásquez. Op. cit. p. 201.

${ }^{113}$ Educación Colombiana. Op. cit. Resolución No. 23 de 1911 p. 45.

${ }^{114}$ Ibídem Ley No. 114 de 1913 p. 49.

${ }^{115}$ Ibidem p. 65 .
} 


\section{El general Pedro Nel Ospina}

Es en el gobierno del general Ospina (1922-1926) cuando precisamente comienzan a manifestarse esas presiones que venían gestándose y anunciándose en las décadas precedentes. Las exportaciones de café saltan de 1.162 .000 sacos en 1916 a 1.942 .000 en 1925, año en que se encontraban sembradas 183.000 hectáreas con 350 millones de cafetos $^{116}$. Ciertamente durante la administración Concha (1914-1918) la industria se había resentido, debido a la poca atención que el gobierno prestó a su desenvolvimiento y a la crisis mundial del año 20; pero con el general Ospina, la economía reasume su dinámica expansiva. En el año de 1922 Colombia entra en la era del petróleo al instalarse, tras desventajosa negociación con la Tropical Oil Company, la primera refinería en Barranca. Correlativamente ingresa en forma definitiva en la órbita financiera de los EE.UU., de la cual el país se había mantenido alejado por la afrentosa separación de Panamá y por los tradicionales vínculos con Inglaterra, aunque ya desde el gobierno de Suárez (1918-1922), el Estado colombiano empieza a guiarse por "la Estrella Polar del Norte" y en 1920 los banqueros norteamericanos conceden los primeros préstamos a entidades estatales por una suma que superaba los 10.000 .000 de dólares ${ }^{117}$.

No obstante los hombres de negocios estadinenses no disimularon en aquel momento sus prevenciones sobre la política financiera de sus clientes, y pusieron como condición para llegar a un acuerdo más amplio la racionalización y modernización fiscal. De allí que, en 1923, el general Ospina invitara a una comisión financiera norteamericana para adelantar estudios sobre la materia, y para formular las recomendaciones pertinentes. Fue la llamada Misión Kemmerer.

Los miembros de la misión —dice Rippy_- "terminaron sus investigaciones y brindaron sus recomendaciones en el lapso de unos meses y antes de acabar el año casi todas sus sugerencias se traducían en leyes" ${ }^{118}$ se funda el Banco de la República como Banco Central y entidad reguladora exclusiva de la emisión; se reorganiza la contabilidad nacional mediante la creación de la Contraloría General de la Nación, y se adopta un sistema presupuestario. "Con la comisión --dice Abel Cruz Santos- se inicia en Colombia la intervención del Estado en las actividades crediticias" ${ }^{119}$. No obstante, los banqueros extranjeros mantuvieron sus reservas, y su oferta no supera la de los años anteriores. Pero en 1926, alucinados con la publicación de un boletín sobre las finanzas públicas y los ferrocarriles en Colombia que edita el Departamento de Comercio, ofrecen al gobierno colombiano un préstamo de 33 millones de dólares ${ }^{120}$, y las inversiones norteamericanas alcanzan la suma de 80 millones de dólares, cuando en 1920 eran apenas de unos 30 millones $^{121}$. Si a estas cifras se suman los 25 millones otorgados por el gobierno norteamericano como indemnización de Panamá, y se recuerda el hecho de que los ingresos del gobierno central se aumentaron notablemente, se entenderá fácilmente por qué la época ha sido llamada la "Danza de los millones". Las inversiones públicas efectuadas con estos dineros se dirigieron principalmente a la construcción de vías de comunicación y desencadenaron un proceso de desarrollo económico sin antecedentes en la historia del país.

\footnotetext{
${ }^{116}$ Absalón Machado. Op. cit. p. 139.

${ }^{117}$ Fred Rippy. El capital norteamericano y la penetración imperialista en Colombia. Editorial La Oveja Negra. Medellín, 1970 p. 144.

${ }_{118}^{14}$ Rippy. Op. cit. p. 145.

${ }^{119}$ Citado por Gerardo Molina. Las ideas liberales en Colombia, Tomo II. Editorial Tercer Mundo. Bogotá, 1977 p. 194.

${ }^{120}$ Cfr. Rippy. Op. cit. p. 146.

${ }^{121}$ Rippy. Op. cit. p. 85. 
De 1922 a 1926 se añadieron 800 kilómetros de vías férreas, con lo cual se obtenía una red de 2.300 kilómetros rebajando sustancialmente el costo del transporte; obra que complementada con la construcción de carreteras, el mejoramiento de las condiciones de navegación por el río Magdalena, la modernización de puertos, y sobre todo con la iniciación de la aviación comercial, la comunicación inalámbrica y la radiodifusión, llevan a Colombia por fin, al siglo XX.

La industria naturalmente no fue la excepción en este acelerado proceso de crecimiento. De una parte, la política económica seguida por Ospina creó un clima de confianza tanto para empresarios nacionales como extranjeros. De otra parte, las inversiones hechas por el Estado en obras públicas estimularon la ampliación del mercado interno, dinamizado ya por los ingresos cafeteros. En 1927, Bogotá tenía 200 fábricas, Medellín 117, Barranquilla 91, Cali 97 y en otras ciudades donde la industria no existía una década atrás, se instalaron unas 75 factorías $^{122}$.

Sin embargo, la agricultura, excepción hecha del café, no sufrió en este período modificaciones sensibles. En 1915 los alimentos agrícolas de consumo directo representaban el $46 \%$ del valor total de la producción y el $65 \%$ del área sembrada; en 1925 el valor total de la producción era del 34\% y el área sembrada no varió. El café, por el contrario, experimentó durante el mismo lapso un desarrollo excepcional. En 1915 la superficie sembrada en café representaba un $9 \%$ del área cultivada del país y en 1925 el café ocupaba el $15 \%{ }^{123}$. Con todo, el incremento de la industria comenzó a estimular progresivamente la agricultura comercial y particularmente los cultivos de algodón, cebada, caña de azúcar, etc. ${ }^{124}$.

Ahora bien, la formidable transformación descrita desencadenó varios procesos de innegable importancia. En primer lugar, el crecimiento de la industria y de la inversión en obras públicas demandaron grandes contingentes de mano de obra campesina, que halagadas por los altos salarios ofrecidos en esos sectores iniciaron una inmigración sin precedentes. Un obrero textil ganaba en Medellín en 1925 un salario diario de 52 centavos, un jornalero agrícola 25 centavos $^{* 125}$.

Ahora bien, la demanda de fuerza de trabajo corría paralela con la demanda de alimentos e insumos de origen agrícola, y por tanto, los grandes propietarios vieron crecer de la noche a la mañana su poder comercial; los precios de los productos agrícolas se dispararon hacia arriba, y el Congreso aprobó la célebre "Ley de Emergencia en 1926 autorizando la supresión o reducción de los derechos de aduana que pesaban sobre los productos alimenticios.

En segundo lugar, la prosperidad general del país desató una gran inflación ${ }^{126}$ que afectó a las clases asalariadas. En Bogotá, por ejemplo, entre 1923 y 1929, los precios de la carne y de los productos lácteos, aumentaron en un $90 \%$ y los salarios en un $12 \%{ }^{127}$. El deterioro de los salarios reales creó un gran desasosiego en la clase obrera que se había

\footnotetext{
${ }^{122}$ Bejarano. Op. cit. p. 24.

${ }^{123}$ Ibídem p. 23-26.

${ }^{124}$ Ibídem p. 25.

* Hoy se discute si esa demanda de fuerza de trabajo ocasionó escasez de brazos en tas zonas rurales, pero lo que parece objetable es que el desplazamiento campesino mejoró la capacidad de negociación y estimuló las reivindicaciones de los trabajadores del campo. Cfr. Bejarano. El fin de la economía exportadora. En Cuadernos Colombianos No. 6. Medellín. Editorial Lealón, 1975 p. 26.

${ }^{125}$ Poveda Ramos. Op. cit. p 44.

${ }^{126}$ Cfr. Hugo López. La inflación en los años veinte. En Cuadernos Colombianos No. 5. Año II, primer trimestre de 1975. Editorial Lealón, Medellín, 1975.

${ }^{127}$ Urrutia. Op. cit. p. 188
} 
fortalecido numérica y organizativamente, de tal manera que la agitación socialista y liberal de oposición fructificó aceleradamente.

En efecto en 1924 los trabajadores de la Tropical Oil Company declararon una huelga en Barranca y aunque la compañía logró un acuerdo con los obreros, despidió a 1.200 de ellos. En 1927 vuelve a estallar la huelga. El gobierno encarcela a los principales dirigentes y en un intento por restablecer el orden la policía mata dos obreros y hiere a 8. En 1928, los trabajadores de la United Fruit Company se lanzan a la huelga y de los enfrentamientos con la fuerza pública resultan 40 muertos, 200 heridos y 500 presos $^{128}$. Fueron también significativos los movimientos de los trabajadores del río Magdalena y de los ferrocarriles, pero no tuvieron la envergadura de las huelgas contra las compañías norteamericanas. En realidad los gobiernos conservadores se mostraron severamente represivos en relación con el movimiento obrero. De 1919 a 1929 sólo 68 sindicatos fueron reconocidos contra 400 entre 1934 y $1938^{129}$.

Los continuados y vigorosos cambios sociales y económicos del período contrastan con la rigidez de la política educativa del gobierno de Ospina. Solamente dos leyes fueron firmadas por el General en esta materia. la Ley 28 de 1925, que decretó las fiestas nacionales de la bandera y de la madre y la Ley 12 de 1926 sobre la enseñanza de la higiene en los establecimientos educativos. La única modificación significativa fue presupuestal. Los gastos del Estado en la educación pasaron de 2.5 millones en 1923 a 7 millones en $1928^{130}$.

Es verdaderamente sorprendente que la evolución social y económica de estos años no hubiera inducido a reformas en la política educativa, cuando era claro que la actividad industrial, comercial, agrícola y estatal requerían trabajadores alfabetizados, mano de obra calificada y cuadros técnicos. "Para el desarrollo de sus proyectos -dice Jaramillo Uribe - la clase empresarial y burguesa necesitaba la colaboración de una élite técnica y de una mano de obra eficaz que no podía suministrar una población analfabeta" ${ }^{131}$. Evidentemente tales demandas no se podían satisfacer plenamente con el estatuto de Uribe, ni con la concepción de la escuela y de la pedagogía que imperaba en la época. Es más, las necesidades educativas no se restringían a las clases adineradas. Las clases medias, silenciosas, tímidas y débiles, surgidas a la sombra de la modernización hacían causa común con las exigencias de adiestramiento de la clase obrera y de alfabetización del campesino.

El rumor de ese conjunto de demandas se tomó claramente audible y paulatinamente se hizo corriente de opinión a través de la polémica que Agustín Nieto suscitó en torno al problema educativo. Inspirado en las tesis de la "Escuela Nueva" nacida a finales del siglo XIX en Europa, Nieto solicitó al gobierno la contratación de una "misión Kemmerer para la educación". "Los adelantos materiales del siglo — escribía en carta a Pedro Nel Ospinavan llegándonos, pero ni el aeroplano, ni el tren eléctrico, ni la draga monstruo, lograrán sacudir la entraña de este pueblo resignado y triste como lo lograría en feliz gestación la reforma sustancial de la escuela que hoy tenemos" ${ }^{132}$. Esa reforma comenzaba para don Agustín con la invitación de una misión extranjera... "Una misión Kemmerer para la educación, una misión belga y suiza, o alemana, dirigida por un hombre conocido por sus obras, por su espíritu, por su ciencia: tal sería la única que podría dejar huella en nosotros"133.

\footnotetext{
${ }^{128}$ Urrutia. P. cit. p. 226.

${ }^{129}$ Ibídem.

${ }^{130}$ Ivon Lebot. Op. cit. p. 33.

${ }^{131}$ Jaramillo Uribe. Op. cit. p. 282.

132 Agustín Nieto Caballero. Sobre el problema de la educación nacional. Selección Samper Ortega de Literatura Colombiana. Sección 5 No. 30. Editorial Minerva, Bogotá, 1937 p. 39-40.

${ }^{133}$ Ibídem p.47-48. 
Ciertamente, el Presidente acogió positivamente la iniciativa y poco después llegó a Colombia una misión alemana, la segunda, compuesta por tres pedagogos altamente calificados, quienes en colaboración con tres respetados educadores colombianos, elaboraron, después de un detenido estudio del sistema educativo, una propuesta de reforma de la estructura, orientación pedagógica y financiación del sector. Traducida a proyectos de ley el gobierno la presenta al Congreso, pero allí naufragó. "Se cree --escribe Jaramillo Uribe--- que tuvo oposición de los intereses privados vinculados a establecimientos educativos y de la Iglesia, no obstante que los miembros de la misión eran católicos"134.

Si bien fue lamentable el fracaso del proyecto impulsado por Agustín Nieto, la polémica que abrió, logró divulgar el cuestionamiento del sistema escolar, objeción que tomará cuerpo en el viraje que el liberalismo dará a la política educativa durante la década siguiente. Por esta razón se hace necesario examinar las tesis centrales que defendió el ilustre educador en aquellos años.

\section{Agustín Nieto y la Escuela Nueva}

El problema educativo del país residía para don Agustín Nieto básicamente en el maestro. En principio la limitación era cuantitativa: "el mal primordial de nuestra escuela reside en la carencia casi total de educadores"135 - Escobar Roa, inspector escolar provincial, y uno de los contradictores más vehementes de la Escuela Nueva respondía: "Sí hay maestros, pero no hay sueldos", argumento que por lo demás se habría iniciado con la respuesta de Pedro Nel Ospina a Nieto Caballero:

"Es mi propósito atender con todo esmero el ramo de la educación popular.., si el Congreso le da al Ejecutivo los recursos indispensables"136.

La falta de originalidad y veracidad de la réplica gubernamental dio ocasión para plantear más a fondo la cuestión.

"No se trata —responde don Agustín- de votar únicamente una partida en el presupuesto... el problema es mucho más hondo... ipreparación inadecuada del magisterio; he ahí el mal concreto" ${ }^{137}$.

Es decir, no se trataba únicamente de una simple inconsistencia numérica entre la cantidad de maestros y la población potencial que requería ser educada, sino del tipo de maestro, de su orientación pedagógica, de su formación técnica. El maestro tradicional, no podía responder a los requerimientos de las nuevas modalidades de desarrollo que se esbozaban.

El autoritarismo, el afianzamiento de premisas ideológicas a partir de las cuales el orden económico, político y social alcanzara plena coherencia era el afán primordial de la pedagogía prevaleciente. La coherencia era un elemento vital para lograr una representación acabada y unánime que se afirmara como condición de reproducción de todo el sistema — que por su naturaleza tendía a perpetuar la distribución desequilibrada

\footnotetext{
${ }^{134}$ Jaramillo Uribe. Op. cit., p. 283.

${ }^{135}$ Agustín Nieto C. Op. cit. p. 41.

${ }^{136}$ Ibídem p.50.

${ }^{137}$ Ibídem p. 67.
} 
de los privilegios-, y de su existencia misma bajo modalidades contradictorias. Que ese consenso básico fuera de carácter religioso o político no modificaba en nada la función. Lo que se planteaba en aquellos años era el antagonismo entre estas dos dimensiones ideológicas por alcanzar la predominancia en la estructura social.

Es evidente que una sociedad articulada por el poder terrateniente, cuyos parámetros reproductivos eran de carácter extra-económico, deba acudir al despotismo ideológico religioso y al poder de la Iglesia para garantizar la identidad de su régimen productivo.

La religión, no sólo como fuerza ideológica sino también como instrumento de poder secular, presidía la organización productiva allí donde la coerción extraeconómica fuera la condición de reproducción. Y era la escuela la instancia social que debía instrumentar esta premisa como fundamento de la representación.

En un régimen de tal naturaleza, la religión y la Iglesia dan un color peculiar a todos los engranajes de representación histórica que una sociedad tiene de si misma. Así, el despotismo del maestro, formado dentro de los más rígidos esquemas epistemológicos, el autoritarismo discursivo del texto y la obtusa y cruel disciplina de los recursos pedagógicos, se entrelazan con una sorprendente coherencia para hacer de su producto, el niño, un mero recipiente de respuestas contra las tensiones y fisuras del sistema. Por esto se explica que el cuestionamiento de la educación que realizó don Agustín Nieto fuera llevado al terreno religioso, pues ni las convicciones del autor, ni la letra de los textos con que expuso su doctrina pedagógica, autorizaban tal desplazamiento.

Para el entonces novel pedagogo, el problema de la educación radicaba, como queda dicho, en la formación de los maestros: había pocos maestros, en relación con la población escolar, pero sobre todo, su preparación pedagógica era sumamente precaria. La "experiencia", aducida como criterio de convalidación del magisterio, era "una aberración, un peso muerto, la cristalización del error, la pereza convertida en hábito"138. "La incompetencia del maestro era lo que espantaba, se ocultara o no, tras el traje talar"139. La experiencia que era en realidad un eufemismo utilizado para defender el conservatismo pedagógico, el entrelazamiento del maestro con la burocracia partidista y los métodos rutinariamente autoritario, no podía seguir sustituyendo la formación científica. Tampoco la identificación del educador con el sacerdote podía contribuir a la solución del problema instruccionista. Nieto Caballero, sin embargo, evitaba con rigurosidad un enfrentamiento religioso porque sabía que en este campo le era imposible una controversia exitosa.

Pero los publicistas del sistema sabían de su parte, que los planteamientos de la Nueva Escuela, si bien no atacaban en sí misma a la religión, eran un expediente poderoso contra el orden social sedimentado con auxilio del poder religioso, razón por la cual provocaban al crítico con una argumentación maniquea. Aunque don Agustín no se diera cuenta cabal, sus ideas sí entrañaban una modificación sustancial no sólo de la escuela sino del rumbo que llevaba el país. ¿Cuáles eran en rigor los planteamientos de la Escuela Nueva?

\section{a. La cuestión religiosa}

\footnotetext{
${ }^{138}$ Agustín Nieto C. Op. cit. p. 22.

${ }^{139}$ Ibidem p.24
} 
Los defensores de oficio de la hegemonía tildaron el cuestionamiento de liberal, en la acepción partidista y burocrática del término, lo que equivalía, en el lenguaje de la época, a una acusación abierta de sectarismo antirreligioso emparentado con el protestantismo, la carencia de moral y, soterradamente, a una sindicación de ateísmo. Nieto Caballero, que fue ciertamente un liberal en política y que contribuyó a formar ideológicamente varias generaciones de liberales, carecía de espíritu banderizo. Más que un liberal decimonónico era un reformista equilibrado, tolerante y pragmático a la manera de Dewey. Por ejemplo, con ocasión del proyecto de creación de la comisión pedagógica que él como nadie había agitado, el gobierno quiso dar participación a la "minoría política" en su seno, es decir, al liberalismo; don Agustín Nieto elevó inmediatamente su voz de protesta contra la pretensión de hacer prevalecer el criterio político frente a la formación científica de los miembros. El proyecto "debiera decir que para la escogencia, del personal de la comisión no se tendría nunca en cuenta la afiliación partidista de los individuos, sino su significación personal..." ${ }^{140}$.Pero esta lección de tolerancia liberal no era fácilmente entendible en la atmósfera de los años veinte: El Nuncio Apostólico hizo pública una prevención amenazante si el Ministro de Instrucción, dada la participación de la minoría política liberal en la comisión, tomaba medidas "no ajustadas al Concordato"141

En realidad, el modelo ideal de relación entre la Escuela y la Iglesia era para Nieto Caballero el norteamericano, donde la "Escuela Oficial es de hecho neutra" porque la coexistencia de credos "hace imposible la hegemonía de uno de ellos" ${ }^{142}$. No obstante, "es diferente la situación -agregaba refiriéndose a Colombia - para un país en donde la inmensa mayoría practica una sola religión. Allí, en nuestro sentir, debe darse instrucción religiosa en la escuela... Aunque no debían obligarse a unidades aisladas, por poco numerosas que ellas fueran, a predicar y a amar lo que practica y ama la mayoría por inmensa que ella sea"143.

Ahora bien, el respeto a las realidades sociales e históricas no implicaba legitimar la subordinación de las órbitas ni cerrar el paso a los progresos de la ciencia acudiendo al argumento de las mayorías. La ciencia y la religión no se podían contradecir salvo cuando la religión se hacía una fuerza material que obstaculizara el progreso ${ }^{144}$. Pero, para Nieto Caballero ese parecía ser el caso de Colombia en los años veinte.

Entonces, en nombre de la ciencia, positiva, pragmática y neutra, inicia un ataque contra una estructura social y educativa que producía un individuo rutinario y medroso, incapaz de ser asimilado por las nuevas fuerzas que pugnaban por modelar la sociedad y acude al expediente de la tolerancia religiosa para exponer un programa educativo evidentemente antagónico con los intereses de un orden económico e ideológico condenado por la industrialización. En síntesis, la formación de un ciudadano para la nueva sociedad era objetivo que se agazapa tras la Escuela Nueva.

\section{b. La reforma pedagógica}

En principio Nieto Caballero no abogaba por la revolución educativa global, sino por una modificación sustancial en el aspecto pedagógico, y para tal efecto apoyaba la comisión extranjera. El adiestramiento de un grupo selecto de maestros colombianos que se

\footnotetext{
${ }^{140}$ Agustín Nieto C. Op. Cit. p. 102.

${ }^{141}$ ibídem p. 33

${ }^{142}$ Ibídem p.46.

${ }^{143}$ Ibídem p. 97.

${ }^{144}$ Ibídem p.48.
} 
responsabilizaran a su vez de amplificar sus conocimientos instruyendo nuevos contingentes de pedagogos, era la estrategia prevista. La reorganización institucional del Ministerio de Instrucción, y las reformas a la educación secundaria y superior eran las consecuencias de la gran transformación pedagógica que proponía ${ }^{145}$.

El aspecto que debía ser renovado totalmente era la metodología de la enseñanza, ni siquiera su contenido: ${ }^{146}$

“... en pedagogía hemos llegado al reinado de la mediocridad y en él continuaremos mientras el método dogmático no ceda al intuitivo y experimental" decía Nieto Caballero al comentar el perfil de la escuela y sintetizar sus esperanzas de cambio.

Era el grito de guerra contra aquellos métodos pedagógicos que traducían un ordenamiento social rígido: contra el dogmatismo no era otra cosa que su geometría ideológica, la apología silenciosa de las jerarquías y la premisa mayor de la autoridad y de la fuerza.

Una sociedad de tal naturaleza no requería para su reproducción la modificación sistemática de su aparato productivo, no requería de una racionalidad experimental y pragmática; su reproducción no rebasaba los límites de su producción convencional pues el esquema de acumulación de capital giraba en torno a una acumulación que revertía necesariamente en el poder territorial; la energía humana y animal bastaba para poner en marcha la producción. Tan sólo se justificaba y se exigía una revolución en las comunicaciones, pues siendo como era el capital comercial el capital prevaleciente, la circulación, el cambio y el consumo de mercancías era primordial. El carácter de la producción, espasmódico, consuetudinario no exigía, como lo exigiría la industrialización, la incesante innovación tecnológica no sólo en los instrumentos sino en todo el ámbito productivo. Pero ello requería una nueva mentalidad de las clases dirigentes y de toda la población. La nueva mentalidad no se invocaba como el caprichoso interés de un grupo, sino como un imperativo popular. La Escuela Nueva "tiende la mano al obrero y al capitalista, al negro, como al blanco, al católico como al protestante y al judío"147. La interacción con la máquina, la relación con el salario, con el sindicato, la tensión de la vida colectiva, eran parte del hombre nuevo tanto como lo eran la invención de nuevas técnicas, el descubrimiento y aplicación de nuevas teorías, la administración de personal, el manejo monetario, los horizontes de la acumulación, en fin, todo lo que traía aparejada la industrialización. Lo que proponía don Agustín era en realidad una subversión valorativa mediante un rompimiento con los viejos métodos pedagógicos que consagraban el "maestro dictador", el texto reverencial, el alumno mustio, en fin, que avalaban una pirámide y más que a ella, al vértice superior.

La reconceptualización de la pedagogía derivada de los trabajos de Decroly, Giner de los Ríos, Cassio y Altamira, Piaget, Dewey y Faunconnet, que en Colombia aclimataron además de Nieto Caballero, Rafael Bernal Jiménez y Tomás Cadavid, fue un gran alegato contra el oscurantismo, la pasividad, el despotismo; un gran esfuerzo por poner la escuela al servicio de la vida, es decir de las nuevas circunstancias sociales que emergían inquietas en la primera postguerra.

La educación era para ellos un complejo vital en que debían trasegar todos sus elementos, expresarse todas las inquietudes por disparatadas que ellas fueran. En fin,

\footnotetext{
${ }^{145}$ Ibídem pp. 126, 134, 160.

${ }^{146}$ Ibídem p. 13.

${ }^{147}$ Ibídem p. 114.

Digitalizado por RED ACADEMICA
} 
debía ser — para decirlo en sus palabras - "el laboratorio de la vida cotidiana y no el reflejo deformado de ella".

A pesar de la gran atención en los aspectos comunitarios de la educación, el nuevo enfoque buscaba obstinadamente la atención particular, el desarrollo de la potencialidad individual mediante el énfasis de la personalidad diferencial del alumno. Para ello se debía apelar al diseño de programas pedagógicos y a la adopción de métodos concordantes con la estructura sensorial y cognoscitiva del niño que extrae de su misma actividad los elementos para el aprendizaje.

Se llegó por este camino a formular la célebre concepción activa y autorreguladora de la educación, eje sobre el cual se montó la experiencia del Gimnasio Moderno y que, en 1936, se impondrá como modelo de la educación pública. La combinación de los centros de interés del alumno eran los módulos a partir de los cuales se impartía una enseñanza globalizada que permitiera deducir de la vida real y palpable una enseñanza más práctica, más útil y más abierta.

En fin, el empeño esencial de la Escuela Nueva era desvincular al maestro de una óptica que reñía con las perspectivas de una sociedad moderna atravesada de lado a lado por la lógica de la industrialización.

"La Escuela Nueva busca por sobre todo un amable desenvolvimiento del espíritu de cooperación social. Así, en las clases no se impone ya aquel trabajo aislado y silencioso de cada alumno, ni aquella torpe repetición en coro que nos vino de la escuela china. Reina allí la animación de un taller. Es aquella una verdadera colmena con su fecunda actividad, desordenada en apariencia. No hay pues, en la Escuela Nueva brazos cruzados, posiciones fijas, labios sellados por orden superior. El niño vive un ambiente de libertad fecunda, en una pequeña sociedad embrionaria que lo prepara para la sociedad del futuro" 148

La imagen que utiliza Agustín Nieto para ilustrar el espíritu de la Escuela Nueva dista mucho de ser inocente. Se trataba en verdad del embrión de una nueva sociedad, más estrictamente de una nueva forma de cooperación social basada en el taller, donde la actividad y la iniciativa "fecundas" procedieran de cada individuo y no de un ordenamiento autoritario y superior. Era una nueva ética la que echaba raíces a través del enfoque pedagógico. La sociedad futura que se preparaba en el aula se parecía sin duda más a un taller que a una hacienda; allí la cooperación y la iniciativa eran la condición de la fecundidad; aquí lo eran el aislamiento y el servilismo. Don Agustín gustaba repetir que el problema era no sólo instruir sino educar y con ello quiso decir que a la instrucción debía agregarse el valor moral, la voluntad de engrandecimiento y la lealtad para cumplir los compromisos $^{149}$.

La escuela no debía preparar "sólo para leer y contar", como lo exigiría una sociedad pastoril - que se limitaba a exportar "frutos y raíces raras" sino que debía transgredir estas funciones para adiestrar al individuo en la investigación, para inculcar el hábito del trabajo, la ética del éxito y la competencia, los valores prevalecientes en una sociedad guiada por la lógica y el sentido del valor del cambio.

Don Agustín Nieto defendía entonces una pedagogía y un maestro que combinara "sabiamente" la instrucción práctica con la educación moral para producir un ciudadano

\footnotetext{
${ }^{148}$ Ibídem p. 132.

${ }^{149}$ Ibídem p. 89-90 
integral, un hombre nuevo. La educación práctica contribuía a preparar al individuo para una vida "útil, intensa, expansiva" basada en la investigación personal, en el "experimento comprobatorio, desterrando todo estudio que recargue la memoria sin prestar atención a la disciplina personal". La educación ática aporta la cultura clásica, los sentimientos humanitarios, el arte, "el embellecimiento improductivo del espíritu, las alas "inútiles" de la imaginación" $" 150$.

"El momento histórico —agrega- pide hombres eficaces, trabajadores de músculos recios, empresarios audaces.. - pero la patria también pide hijos en que la preparación científica esté aunada al carácter firme del espíritu comprensivo de los problemas sociales..."151.

El énfasis humanista, teorizante, complementario de la dimensión práctica no fue para don Agustín un nuevo prurito enciclopédico, un mero adorno, sino por el contrario, un fin positivo.

"Recordad, señores industriales, que la superioridad técnica de ciertos países reside precisamente en su subestructura científica que forma los moldes de su química, de su metalúrgica, de su agricultura... En la raíz misma de las especialidades prdcticas que pueden darle un empuje de progreso a la Nación estd la seria preparación científica, es decir, la disciplina mental del conocimiento que respalda y guía la obra material" ${ }^{\prime 152}$.

Se encuentra aquí, en esta valiente y cristalina argumentación la clave para explicar el sentido de la obra que se proponía llevar a cabo la Escuela Nueva. El rompimiento con la pedagogía tradicional, la memorización, el dogmatismo del traje talar, era el hilo conductor de una nueva concepción del mundo, una ideología que situaba al individuo en una sociedad donde el experimento, la iniciativa personal "fecunda", la libertad de expresión sirvieran de atmósfera a una forma de cooperación social, que el insigne pedagogo simbolizó en el taller.

La exposición de sus ideas fue el anuncio, y al mismo tiempo, la preparación de una época que se apartará de los caminos que la obsoleta pedagogía había previsto como futuro de la Nación.

\section{La crisis del 30}

Al comenzar el año 28, nada hacía presentir el advenimiento de una crisis. La situación general de la economía del país era mis que satisfactoria. La producción cafetera se había consolidado, el comercio exterior ofrecía índices alentadores, la industria se hallaba en pleno auge, el mercado interno se ampliaba incesantemente y las inversiones norteamericanas pasaban de los 200 millones de dólares ${ }^{153}$. El optimista panorama era empañado tan solo por algunas inquietantes manifestaciones de inconformidad social como la huelga de los trabajadores del banano contra la United Fruit, o la intensa agitación socialista que llevó al gobierno de Abadía a expedir decretos de alta policía y la célebre Ley Heroica ${ }^{154}$.

\footnotetext{
${ }^{150}$ Ibídem p. 130.

${ }^{151}$ Ibídem p. 132.

152 Ibídem p. 133.

${ }^{153}$ Rippy. Op cit. p. 85.

${ }^{154}$ Cfr. Gerardo Molina. Op. cit. p. 234.
} 
Pero al año siguiente, 1929, los síntomas de una crisis de hondas repercusiones comienzan a hacerse sentir inequívocamente. Los préstamos e inversiones norteamericanas se detienen bruscamente y en consecuencia los trabajos de obras públicas que venían adelantándose se afectan en idéntica proporción. En 1928 el ingreso total del Estado era del orden de 107 millones de pesos, de los cuales 33 millones estaban representados por ingresos extraordinarios. En 1929 los ingresos totales se habían reducido a 75 millones y los ingresos extraordinarios eran nulos. Para 1928 el Estado había hecho inversiones superiores a los 60 millones en obras públicas, es decir más de la mitad de sus ingresos totales. En 1929, estas inversiones en obras públicas caen a 30 millones $^{155}$.

De otra parte, la crisis mundial desencadenada a partir de octubre de 1929 afecta notablemente los precios del café y los ingresos provenientes de este sector de exportación, que constituían ya para esos años más del 700/o del total del comercio exterior. En 1929, por ejemplo, el país recibió por 2.800 .000 sacos de café exportados la suma de 75 millones de dólares, en 1930 por 3.200 .000 sacos recibió apenas 60 millones de dólares ${ }^{156}$.

Este conjunto de fenómenos tuvo serias implicaciones en la marcha general de la economía. La parálisis de las obras públicas se tradujo en el licenciamiento de miles y miles de obreros que se vieron enfrentados al desempleo. Muchos regresaron al campo agravando el conflicto agrario, que venía acrecentándose, y otros, dirigiéndose a las ciudades y convirtiéndose en desempleados, contribuyeron a agudizar el enfrentamiento entre patronos y obreros. El movimiento campesino y el movimiento obrero cobran entonces nuevos bríos y la agitación socialista y liberal conquista un vasto auditorio. Gaitán y María Cano recorren el país sembrando la inconformidad y la esperanza. Los campesinos se lanzan a la lucha por la tierra y son invadidas cientos de haciendas, los obreros amplían sus demandas y el clima laboral se enrarece. Los sectores medios de la sociedad se ven afectados por la inestabilidad económica y pronto el movimiento estudiantil universitario se lanza a la calle en demanda de una gran reforma de la universidad.

Desde otro punto de vista, la industria acusa el receso de la inversión en obras públicas. El mercado de bienes de consumo se restringe notoriamente y el ritmo de reproducción y ampliación del capital industrial decae. Paralelamente las restricciones del comercio exterior impuestas por la crisis del año 29, agravan las condiciones de producción industrial que dependía en un 600/o de los suministros del exterior. El proceso de industrialización entra en una crisis de la que sólo saldría hacia 1933. En 1932 el volumen físico de la producción industrial "fue tan sólo el $38 \%$ del nivel correspondiente a $1929^{\prime \prime 157 . ~}$

Los empresarios se vieron obligados en estas circunstancias a tomar medidas drásticas que contribuyeron a complicar aún más el tenso clima social: reducción de salarios, ampliación de la jornada de trabajo, licenciamiento de obreros, etc. Estas disposiciones fueron complementadas por otras de carácter técnico y financiero que implicaron la disminución de la demanda de insumos industriales ${ }^{158}$.

\footnotetext{
${ }^{155}$ Melo J. O. La República Conservadora, Op. cit. p. 93-94.

${ }^{156}$ Ibídem p.77.

${ }^{157}$ Poveda Ramos. Op. cit. p. 54.

${ }^{158}$ Bejarano. La Economía en el siglo XX. Op cit. p. 47.
} 
La crisis de la industria no afectó solamente a la clase obrera y a los sectores medios, sino también secundariamente a las clases rurales: al declinar las demandas urbanas de alimentos, la producción agraria se ve golpeada. "Los precios de los productos agropecuarios - dice Bejarano- comenzaron a caer como resultado del exceso de oferta del sector agrícola... lo cual contrajo aún más el mercado para la industria“" ${ }^{159}$.

Los efectos de la crisis económica del año 29 aceleraron y amplificaron los reclamos populares y generalizaron el malestar social al no traducirse en reformas que hubieran aliviado la tensión - "La clase obrera se hallaba descontenta con su baja capacidad de consumo; la pequeña burguesía productora se estaba empobreciendo; la nueva clase industrial buscaba ascender más firmemente y las viejas clases poseedoras de grandes extensiones de tierra oponían una resistencia sistemática y agresiva a todo intento de reforma" — dice Darío Mesa— comentando la situación hacia 1929-1930 ${ }^{160}$.

El partido conservador, que había gobernado con mano fuerte al país durante casi medio siglo, fue incapaz de encontrar en aquella encrucijada una salida distinta a la represión. La matanza de las bananeras, la citada ley heroica y los sucesos del 8 y 9 de junio de 1929 donde resultó muerto un estudiante, son ejemplos claros de la forma como el gobierno enfrentó la inquietud social y las demandas de reforma. El régimen conservador cae progresivamente en el desprestigio - La impopularidad de las medidas tomadas por Abadía Méndez acentúan el deterioro de un partido que gobernaba desde hacía medio siglo. En estas circunstancias el conservatismo se divide. La Iglesia que tradicionalmente elegía al candidato conservador, acorralada por la incertidumbre, no acierta a salvar al partido de la hecatombe.

El liberalismo, por su lado, arrecia el cuestionamiento contra los programas conservadores. López Pumarejo, haciéndose eco de la protesta generalizada, escribe: "La revolución económica no tiene por base aquí en Colombia las teorías de Lenin y de Marx, sino el abuso del crédito exterior, ni sus más activos agentes son los dirigentes del movimiento socialista, sino los ministros de Hacienda y Obras Públicas. Como es el mejor propagandista de este movimiento el Ministro de Guerra. El edificio de nuestra prosperidad levantado a debe, no puede descansar sobre la incomprensión y el capricho de nuestro mandatarios" ${ }^{\prime 161 *}$.

\section{Enmiendas a la Reforma de Uribe}

Sin embargo, el gobierno de Abadía Méndez era sordo al clamor reformista y a la peligrosa situación del conservatismo. La política educativa del último cuatrienio de la hegemonía no fue en general una excepción al terco inmovilismo.

En efecto de 1926 a 1930 el gobierno sanciona las siguientes normas en materia educativa: Ley 56 de 1927 por la cual se dictan algunas disposiciones sobre instrucción pública; el Decreto 1779 de 1927 prohibiendo que en los locales de las escuelas se realicen actos diferentes a los que están destinados; la Ley 86 de 1928 sobre academias nacionales, Sociedad Geográfica y otras disposiciones entre las cuales se hallan la lucha

\footnotetext{
${ }^{159}$ Ibídem p.48.

${ }^{160}$ Darío Mesa. Treinta años de Historia de Colombia. En: Ensayos de Historia Política Contemporánea. Editorial La Pulga, Bogotá. 1976. p. 27.

${ }^{161}$ Citado por Gerardo Molina. Las ideas liberales en Colombia. Tomo III. Editorial Tercer Mundo, Bogotá, 1978. p. 227.

* El lector interesado en ampliar la información sobre la crisis del treinta y sus efectos, puede remitirse a los trabajos de Carlos Esteban Posada. "La Crisis del Capitalismo Mundial y la deflación en Colombia", en Revista Cuadernos Colombianos Nos. 10 - 11; véase también, Oscar Rodríguez, "Efectos de la gran depresión sobre la industria colombiana”; Medellín, Editorial La Carreta.
} 
contra el alcoholismo, "que es la lepra de las clases obreras, causa principal del aumento de la miseria y la criminalidad"; la Ley 13 de 1928 por medio de la cual se fomenta el ahorro escolar; la Ley 23 de 1929 que provee el mejoramiento de las escuelas normales; y el Decreto 865 de 1930 que emite algunas normas sobre la enseñanza de la historia y la geografía patria. Exceptuando la Ley 56 de 1927 y la Ley 23 de 1929, la legislación escolar del cuatrienio de Abadía prolonga la tendencia que los gobiernos conservadores desde el general Reyes había observado. Aunque estas leyes no introdujeron grandes novedades al sistema educativo, son interesantes de analizar.

La Ley 56 de 1927 constituye sin duda la más importante enmienda de la política educativa desde las reformas de Uribe. En primer lugar el Ministerio de Instrucción y Salubridad Pública cambia su nombre por el de Ministerio de Educación, definiendo así el campo propio de la actividad estatal en estas materias y se transforma al Consejo Universitario en una entidad consultiva para todo el ramo de la educación pública. La ley tuvo un significado especial en cuanto a la redefinición del carácter de la educación primaria y de la población infantil susceptible de ser educada. El artículo 4o. dice que los padres están obligados a proporcionar un mínimo de educación 'que siente las bases necesarias para la vida", pero quedando en libertad de escoger entre la escuela pública o privada, y la enseñanza en e] hogar. Es decir, los padres quedaban obligados a dar una educación básica a los niños por cualquier medio, deber que en el estatuto de Uribe no existía. De otro lado, la ley prohibió el trabajo de niños y niñas menores de 14 anos, "a menos que los niños hayan cumplido 11 años y presenten el certificado" que demostrara que había adquirido el mínimo de enseñanza prescrita por la misma ley. Así mismo, el Artículo 80. obligó a los propietarios de haciendas donde "hubiere 20 niños o más en edad escolar" a suministrar gratuitamente un local para el establecimiento de una escuela rural.

La reglamentación sobre el trabajo infantil estuvo quizás destinada a atenuar los abusos susceptibles de cometer sobre esa población en una coyuntura económica caracterizada por una gran demanda de fuerza de trabajo como aquella que rigió hacia 1925-28. La obligación de los hacendados de contribuir a la educación rural expresa la preocupación del gobierno por el alto grado de analfabetismo rural en un momento en que la migración a la ciudad y la importancia de la agricultura comercial crecían notablemente. Sin embargo, esta norma parece también responder a las reivindicaciones que el campesinado planteaba y que el gobierno deseaba atenuar.

De todos modos, las medidas testimoniaron de alguna manera la ansiedad del gobierno por atender los graves problemas que afrontaba en el campo educativo, cuyo divorcio con el sistema económico y con las demandas sociales se hacía ostensible. Para Alejandro López por ejemplo, dice Gerardo Molina, era una "verdad trivial aquella de que la ciencia del trabajo está emparentada con la función docente".., la escuela debía crear "un poder motor" en la economía ${ }^{162}$.

La Ley 56 de 1927, avanzó sobre otros aspectos del sistema educativo reglamentando la educación secundaria y universitaria. El Artículo 9o. limitó la facultad de conceder títulos a los colegios oficiales o privados que se sujetaran a las disposiciones estatales, y estableció por medio del Artículo $10^{\circ}$. un examen previo elaborado por el Ministerio de Educación para los bachilleres que deseaban ingresar a la universidad. Por último homologó los títulos de las universidades públicas y privadas, siempre que éstas hubieran sido reconocidas oficialmente.

\footnotetext{
${ }^{162}$ Gerardo Molina. Op. cit. p. 210.
} 
Es evidente que estas últimas normas de la Ley 56, estaban enderezadas a reglamentar tímidamente la "libertad de enseñanza" de que el sector privado de la educación gozaba ampliamente. La necesidad de unificar, así fuera mínimamente, los contenidos y los fines de la educación es palpable en el espíritu de esa ley. Las demandas del aparato productivo así lo imponían. La iniciativa privada en materia de educación comienza a manifestar sus límites y el Estado a descubrir la función de adecuar el sistema educativo a las nuevas realidades planteadas por el sistema económico.

A esta misma tendencia obedecía la Ley 23 de 1929 que procuró el mejoramiento de las escuelas normales. En primer término autorizó al ejecutivo "a formar un pénsum que esté en armonía con los adelantos pedagógicos", y a "apropiar de los presupuestos departamentales", las sumas necesarias para la dotación de laboratorios, museos y bibliotecas en cada una de las normales, y en segundo lugar, elevó sustancialmente el número de profesores para todas las escuelas, aumentando sus sueldos e incrementando el número de becas. Así mismo propendió a elevar la calificación de los profesores de las normales fomentando cursos de vacaciones y estableciendo el premio al maestro.

En realidad estas dos leyes no fueron importantes tanto por los cambios introducidos en el sistema educativo sino por la significación que entrañaban como testimonios de una tensión que lamentablemente registraron débilmente. Era la tensión entre la escuela y la fábrica; entre las demandas populares de una educación masiva y los recursos de los gobiernos, entre los deberes del Estado y los derechos de la Iglesia, entre la educación pública y la educación privada. En síntesis, el régimen conservador fue temerariamente refractario a todo tipo de reformas educativas a pesar de que los cambios económicos y sociales, que había contribuido a impulsar, eran inobjetables.

\section{El movimiento universitario}

Contra esta conducta francamente retardataria reaccionó el movimiento estudiantil hacia 1929.

El estudiantado universitario, que después de haber contribuido al derrocamiento de Reyes en 1910 entra en un período de sopor, salta en 1929 al primer plano de la actividad política nacional encabezando un movimiento de rechazo contra la hegemonía conservadora.

Con ocasión de un gran movimiento cívico desatado en Bogotá, en junio de 1929, dice Gerardo Molina: "Ios estudiantes, que se habían puesto a la cabeza de la protesta, tenían en sus manos el control de la ciudad, y en la noche de ese día el alumno de derecho, Gonzalo Bravo Páez, cayó víctima de un disparo oficial” ${ }^{163}$. Los sucesos tuvieron amplia repercusión y la ciudadanía pidió la destitución de altos funcionarios "inclusive la renuncia del propio Presidente de la República"164.

Es explicable que el hecho tuviera tal envergadura, si se tiene en cuenta el ambiente explosivo que vivía el país en aquel año. La caída de los salarios, el desempleo, la inflación corrían parejo con la agitación socialista, la oposición liberal, y el desprestigio del gobierno. A la matanza de las bananeras en 1928 y a la represión del campesinado, se sumaba ahora el asesinato de un estudiante. El régimen conservador encuentra un nuevo enemigo: la clase media. Un sector social hijo de la industrialización, del crecimiento del

\footnotetext{
${ }^{163}$ Gerardo Molina. Op. cit. p. 235.

${ }^{164}$ Ibídem.
} 
Estado, del incremento del comercio y del desarrollo de la agricultura, un sector ambiguo y multifacético, avalado por los empresarios y respaldado por el liberalismo, se lanza a la lucha escondido en las banderas del movimiento estudiantil y pone en serios aprietos al gobierno de Abadía.

El movimiento estudiantil venía esbozándose tímidamente desde 1920 al lado de las luchas sindicales, de la agitación socialista y de la oposición liberal. Sus objetivos y medios de acción se inspiraban en el célebre Manifiesto de Córdoba de $1918^{165}$ cuyas ideas expuso y popularizó principalmente Germán Arciniegas en su libro "El estudiante de la mesa redonda" en el cual cuestionaba radicalmente no sólo el sistema educativo vigente, sino todo el régimen social. Por ello se justifica analizar las tesis básicas defendidas por Arciniegas y que adoptadas por el movimiento estudiantil formaron parte de la doctrina liberal en aquellos años.

"El estudiante de la mesa redonda" fue uno de los textos más significativos, que el llamado movimiento de Córdoba, produjo. Con un lenguaje vigoroso Germán Arciniegas convoca a un estudiante de cinco siglos, para hacerle hablar el idioma de los años veinte americano, más estrictamente hispanoamericano: "de México a Magallanes".

Los ideales del estudiante de Córdoba, de Tami Espinosa, han sido los ideales aludidos siempre por el movimiento estudiantil y eludidos siempre por las fuerzas que en el Estado se dan cita la cátedra libre, la renovación del profesorado, la autonomía universitaria, son ideales que al estudiante se le antojan eternos, pues en esa dimensión atormentada y permanente encuentra la alegoría de su propia historia. Es la invitación que hace Arciniegas en las primeras líneas: metámonos en la taberna de la historia donde van los estudiantes de todos los tiempos.

Es un rasgo común de la época (de toda época de transformaciones sociales) ver la historia sin historia, como el porvenir de protagonistas que caminan a grandes zancadas sobre los vértices y los pliegues de un acontecer singular.

Para Arciniegas, pero también para toda su generación de "Los Nuevos" como se le llamó, el estudiante es un "Conversador" que lleva la revolución en el alma, que auna al sentimiento de justicia y al deseo de liberación, el anhelo de sabiduría y la voz contra el orden establecido, contra la pasividad, contra el conformismo.

En realidad, ese era el clima que respiraba la juventud de la primera postguerra. Fue el mensaje que estalló en Córdoba y que en Colombia recogió la Unión de Estudiantes que enterró a Bravo Páez inaugurando las jornadas, del 8 y 9 de junio.

Fueron los estudiantes que combatieron, apenas balbuceantes, a Reyes, y que Arciniegas presenta como los albaceas del espíritu anti-autoritario que inspiró el atentado septembrino: "Los estudiantes que conspiraron contra Bolívar aparecen cada vez que de derrocar una dictadura se trata: contra Mosquera, contra Reyes, contra Rengifo"166.

Es claro que esa generación que transitaba por la universidad de los años veinte tenía ante sí un enorme reto: un régimen político hegemónico y decadente, que prohijaba un

\footnotetext{
${ }^{165}$ El texto del manifiesto estudiantil del movimiento de Córdoba, Argentina, se encuentra publicado en este mismo número en la sección de DOCUMENTOS.

${ }^{166}$ Germán Arciniegas. El estudiante de la mesa redonda. Editorial Suramericana. Buenos Aires, 1971. p. 196.
} 
claustro obscurantista y estrecho. La consistencia entre estas dos dimensiones sociales del poder fue evidente para ellos y revolucionar la última, para proyectarse sobre la primera, su objetivo deliberado. "Su punto de vista (el del estudiante) consiste en mirar el perfeccionamiento de la República como proyección de la universidad, renovando en ésta su contenido social" ${ }^{\prime 67}$.

La dictadura política y el régimen universitario regresivo y conservador iban de la mano. Por eso, toda protesta universitaria, era una reacción subversiva que atentaba contra el orden establecido. "Toda dictadura en nuestra América necesita en primer lugar arrancar la lengua al estudiante" 168 .

Arciniegas atribuía a la universidad una tarea enorme en sus propósitos y significados porque no veía otro sujeto de las transformaciones que se estaban gestando. Veía, ciertamente, el elenco social que se oponía al cambio, y los aliados del estudiante, pero no encontraba la clase social que estaba a la puerta de la taberna estudiantil y que se convertiría en la protagonista central de las modificaciones, que los estudiantes de Córdoba anunciaban y que sin duda iniciaron. "Como siempre ha habido tres maneras de expresión en América frente al conflicto vital. Han hablado los bandidos, los políticos y los estadistas"169. Los bandidos, representados por Sandino... cuyas guerrillas ironizan y piruetean frente a las fuerzas del orden no comprendieron que "lejos de las montañas las ciudades andan de prisa". Los políticos —continúa Arciniegas - vieron que los campesinos eran degollados y se alzaron de hombros. Los grandes estadistas, inventados por los colosos del norte para "remplazar a los generales cojos y mancos", "creyendo intuirlo todo, se colocaron a merced del mecanismo indescifrable, moviéndose sin saber a quién servían, entregando sin saber lo que entregaban... pasaron de la nada a la nada". Así, sólo quedaba el estudiante, "la nueva fuerza capaz de proyectarse con luz propia sobre una sociedad abyecta".

Por eso la universidad fue exaltada como el verdadero sujeto de la revolucion a la que se veía abocada América, que dicho sea de paso, estaba circunscrita a la América Morena, como gusta llamarla. La revolución —escribe - ya no se anunciaba como una rendición política, sino como una revolución universitaria; una revolución contra lo que Arciniegas denominó "el civilismo", es decir, el estado de cosas de la época.

El civilismo era el blanco de la crítica por ser la argamasa con que se tema divorciada la universidad de la vida y atada a la sombra "del bronce de Fray Fernando de Trejo y Sanabria", el modelo colonial de universidad.

El civilismo había dado a la República y a la universidad una conciencia jurídica que era simplemente la noción de la ley abstracta, erguida e inmodificable donde "los nuevos hechos que revelaba el análisis social no tenían cabida". La ley, para los civilistas, dice Arciniegas, era un "fantasma ligado al pasado y a la tradición en lo que tienen de más artificioso" $^{\prime 170}$.

El derecho romano había modificado la anatomía de la universidad negándose a alojar "los anhelos de la juventud.., las inquietudes sociales... las revaluaciones científicas". Ante el estudiante se interponía "un señor gordo con los textos de Papiniano y la fe de los Pandectas para negar el empeño, históricamente avalado de la juventud" ${ }^{171}$.

\footnotetext{
${ }^{167}$ Ibídem. p. 220.

${ }^{168}$ Ibídem. p. 196.

${ }^{169}$ Ibídem. p. 216.

${ }^{170}$ Ibídem. p. 218.

${ }^{171}$ Ibídem. p. 217. 
El movimiento de Córdoba de 1918 y su eco en el movimiento estudiantil colombiano de 1929 urgía la apertura de una ventana por donde entrara la luz de la vida, término que encontraremos una y otra vez en la obra de Arciniegas. La vida para ellos, es decir, para la generación de Los Nuevos, era equivalente a la historia, un instante que se revivía fugaz y esquivo. Por eso perder un minuto en dudar del imperativo histórico era robar un minuto al destino. La historia tenía una existencia que no era lícito escatimar; la historia se afirmaba positivamente y soslayarla suponía ignorarla, desconocerla. "El estudiante no es cívico ni civilista. Simpatiza con Rusia porque Rusia es un argumento de hecho"172. En cambio "el civilismo" no afirmaba más que aquello que fuere afirmado por el hecho legal, la realidad no era una criatura de la historia sino del derecho, una figura producida por el lente jurídico con que se mirara.

En el fondo en la vieja argumentación del positivismo que domina a Arciniegas y que presidió el pensamiento de todos los protagonistas de la República liberal. Es la realidad, una realidad económica y social expresada en los intereses determinados de nuevos grupos sociales la que buscaba una juridicidad propia. Para "el civilismo" los nuevos intereses no tenían existencia, puesto que no eran contemplados por el espacio, los conceptos, ni las realidades jurídicas en que se desenvolvía su historia. Pero es éste precisamente el mérito histórico de esa generación que expresó con fidelidad, digna de mejor suerte, las luchas del capital productivo y las contradicciones que entrañaba. El estudiante de Arciniegas fue el personaje a través del cual la burguesía industrial reclamaba con vehemencia una geografía jurídica que convalidara su emergencia y proporcionara los instrumentos de su propia juridicidad. Detrás del féretro de Bravo Páez iba la República liberal con todas sus banderas. "Detrás de la universidad marchaba la República"173, escribió con toda lucidez Arciniegas.

La hegemonía conservadora "del civilismo" había extrañado "la vida" de la universidad; negaba y perseguía "al observatorio, al laboratorio", a los instrumentos por medio de los cuales se podía dar cuenta de los nuevos intereses que hacían su irrupción en el panorama social.

"Vida" y "Civilismo" se oponían tanto como se contraponían los intereses del liberalismo a los del conservatismo. El estudiante vitalista estaba llamado a desalojar el convencionalismo jurídico de la universidad y de la República, por cuanto no comprendía las nuevas inquietudes sociales y antes bien las suprimía a sangre y fuego.

Arciniegas caracteriza implícitamente la hegemonía conservadora como una dictadura civil y por ello su libro es una apoteósica apología de la trayectoria conspirativa y al fin subversora del estudiantado; un llamamiento aguerrido a asaltar la ciudadela conservadora por medio de la revolución universitaria. La universidad transformada era una herramienta de conocimientos de las nuevas realidades: las nuevas cadencias producidas por las fábricas; un medio de crear un nuevo espíritu jurídico: la nueva lógica del quehacer económico.

La transformación de la universidad era necesaria porque era la única forma de introducir, sin una revolución política, "los fundamentos materiales y morales de la patria". "La universidad debe ser una gran empresa política, con una idealidad nueva, un plan nacional propio, terrígena ${ }^{174}$.

\footnotetext{
172 Ibídem. p. 209.

${ }^{173}$ Ibídem p. 199.

${ }^{174}$ Arciniegas. Op. cit. p. 210.

Digitalizado por RED ACADEMICA
} 
La universidad - dice en otra parte- "debe traer el laboratorio social al aula, pero también debe ir al pueblo para que la ciencia surja de la entraña misma de América "175. Propósito que implicaba desmantelar la vieja estructura universitaria, cambiar los contenidos de sus programas, revolucionar las relaciones de poder en los claustros. La cátedra libre, la elección del profesorado, la autonomía universitaria, eran las palancas que servirían para romper la estatua de bronce de Fray Fernando de Trejo y Sanabria: la manera de "abrir la ventana" por donde entrara la luz de los altos hornos, el ruido de las máquinas de vapor, el humo de las chimeneas. El profesor gordo que regentaba con acartonado despotismo la cátedra de Derecho Romano, debía ser desplazado por el joven profesor que instruía en los secretos del "laboratorio, del observatorio" con razonado discurso, y exponía "las excursiones a otras culturas" con pausada lógica.

El estudiante de 1929 "terminó la leyenda de que eran maestros unos señores que se contentaban con repetir la lectura de textos arcaicos, los anhelos de investigación contenidos por el conservadurismo de los académicos ${ }^{176}$.

Ahora bien, ¿cómo identificaban Arciniegas y el movimiento estudiantil las fuerzas que se atrincheraban detrás de la universidad para defender el orden "civilista" y las fuerzas que reclamaban una nueva universidad, libre, positivista, autónoma, para que la República dejara de ser un "nido de polillas"?

Los generales y los grandes estadistas (Reyes, Ospina, Abadía Méndez, Suárez), símbolos del orden político, afianzaban su poder en el "servilismo de la burguesía y del clero". Un clero encaprichado en mantener una universidad confesional, aislada del desarrollo científico y una burguesía que temía "abandonar el mostrador", una burguesía que moteja a Tami Espinosa de vagabundo, novelero, desaplicado. "La gente que habla desde el mostrador en las tiendas de abarrotes, y constituye la más poderosa corriente del espíritu conservador ha vaciado su pensamiento en esta fórmula: "El estudiante no debe mezclarse en lo político"177.

Pero para Arciniegas y para el estudiante de Córdoba hay otra fuerza que horma al "civilismo": el colonialismo, pieza fundamental en la arquitectura conceptual de aquel movimiento. No se trataba de una nueva postura antiimperialista heredada de la generación del centenario que vivió y sufrió los rigores del águila imperial. Se trataba de una nueva modalidad del colonialismo, "que hace de cada República una colonia económica y una colonia moral"178.

Para él, no era un secreto que los prohombres de la hegemonía conservadora estaban vertebrados directamente al capital norteamericano, que los "grandes estadistas" de América y los agentes de las casas comerciales extranjeras tenían intereses comunes. "Los agentes (comerciales) se convirtieron, de comerciantes, en directores de la opinión pública. Fueron ellos quienes por vender automóviles, neumáticos y repuestos... determinaban a los ciudadanos para que pudieran hacer carreteras troncales, carreteras por los despeñaderos de los Andes y carreteras por el equilibrio de las llanuras, para sus automóviles... El gobierno pedía prestado dinero. Los agentes de los bancos del norte comprometían a los Estados indefensos para que les solicitaran empréstitos. Los hijos de

\footnotetext{
175 Ibídem p. 211

${ }^{176}$ Ibídem p. 212

177 Ibídem p. 209

${ }^{178}$ Ibídem p. 217.
} 
los presidentes y los ministros eran sobornados. Se hacían grandes negocios, se vendían automóviles y se quebraba la moral de las naciones pobres"179.

La crisis de la democracia del sistema político colombiano sólo era recuperable con base en la universidad nueva, porque ésta era la única instancia que podía reflejar la realidad en la política, sin lo cual todo esfuerzo era infructuoso, toda resistencia inútil y toda restauración democrática imposible. La universidad tenía entonces la función de vertebrar la realidad nacional con el sistema político, modificándolo sustancialmente, haciéndolo democrático, y traduciendo las voces de los intereses reales.

Es indudable que detrás de la universidad y de la lucha del movimiento de Bravo Páez iba la burguesía industrial; que la universidad fue una de las armas más eficaces en el enfrentamiento contra el régimen conservador que condensaba los intereses del terrateniente y del comerciante, santificados por la Iglesia y defendidos por las armas. $Y$ hay que decirlo, la República liberal no defraudó, en su primera fase, los anhelos de la juventud que envalentonó, juventud que simbolizaba los sueños de una clase en gestación. La reforma educativa de López, la reforma universitaria, fueron el emblema de la alianza que el capital industrial celebró con sus hijos recién nacidos, pero también el pago que el liberalismo hacía a la juventud por su participación en el derrocamiento de la hegemonía conservadora.

La depresión económica en que se sumió el país a raíz de la crisis del 29, la desastrosa política económica de Abadía, la creciente animadversión contra las medidas represivas, condujeron progresivamente a la división del conservatismo y al fortalecimiento del partido liberal. El resultado fue la bancarrota de la hegemonía conservadora y el triunfo de Olaya Herrera a la cabeza de un movimiento de concentración nacional, que agrupaba a un sector conservador y al grueso del liberalismo incluyendo en él las tendencias socialistas. Se inaugura así la llamada República liberal, un período de profundas y fructíferas reformas del sistema educativo*.

\footnotetext{
${ }^{179}$ Ibídem p. 216.

${ }^{*}$ Para los interesados en continuar con el análisis de la política educativa y el cambio social a partir de 1930. se recomienda el ensayo de Aline Helg, "La educación primaria y secundaria durante el primer gobierno de Alfonso López Pumarejo" 1934-1938 (Proyectos y Realizaciones). Publicado en Revista Colombiana de Educación, No. 6, Primer Semestre 1980.
} 


\section{CONCLUSION}

Vista en su conjunto, la política educativa del régimen conservador en las primeras tres décadas del siglo, se basa casi exclusivamente en el estatuto de Antonio José Uribe. Las modificaciones posteriores son extremadamente discretas y tienden a divorciar cada vez más el sistema educativo de los cambios experimentados por el país en esos treinta años. La Reforma Uribe ciertamente logró adecuar el sistema educativo a las realidades y a las perspectivas de una economía que acusaba los primeros síntomas de industrialización y de recuperación de su comercio exterior, sobre todo basado en el café, pero donde el régimen productivo tradicional era todavía preponderante. Uribe concilió estas tendencias contradictorias en sus reformas y ello explica la sorprendente estabilidad de la Ley Orgánica de Educación. Sin embargo, la industrialización, el desarrollo de la exportación de café y la modernización general del país crearon nuevas situaciones económicas y sociales que la política educativa del conservatismo sistemáticamente soslayó. El divorcio fue denunciado permanentemente por el liberalismo. Don Agustín Nieto Caballero y Germán Arciniegas encabezan movimientos que cuestionan seriamente la política educativa del régimen. Los años 30 fueron testigo de un esfuerzo descomunal del liberalismo por armonizar el sistema educativo con las transformaciones económicas y sociales desencadenadas por la industrialización, y por hacer realidades institucionales las ideas difundidas por la Escuela Nueva y el Movimiento de Córdoba. 


\section{BIBLIOGRAFIA}

ARCINIEGAS, Germán. El estudiante de la mesa redonda. Editorial Suramericana. Buenos Aires, 1971.

BEJARANO, Jesús, A. La Economía en el siglo XX. Ensayo publicado en el Manual de Historia de Colombia. Tomo III, Colcultura, Bogotá, 1980.

El fin de la Economía Exportadora. Ensayo publicado en Cuadernos Colombianos Nos. 6-7-8. Año II. Segundo, Tercero y Cuarto trimestres de 1975. Editorial Lesión. Medellín, 1975.

JARAMILLO, Uribe, Jaime. El proceso de la Educación del virreinato a la época contemporánea. Manual de Historia de Colombia. Tomo III. Colcultura, Bogotá, 1980.

KALMANOVITZ, Salomón. El desarrollo capitalista en el campo colombiano. Ensayo publicado en Colombia Hoy. Siglo XXI. Editores, Bogotá, 1978.

LOPEZ, Hugo. La Inflación en Colombia en la década de los veinte. Ensayo publicado en Cuadernos Colombianos No. 5 año II, primer trimestre de 1975. Editorial Lealón, Medellín, 1975.

LEBOT, Ivon. Educación e ideología en Colombia. Editorial La Carreta, Medellín, 1975.

MACHADO, Absalón. El Café, de la Aparcería al Capitalismo. Editorial Punta de Lanza, Bogotá, 1977.

MELO, Jorge Orlando. La República conservadora. Ensayo publicado en Colombia Hoy. Siglo XXL Editores, Bogota, 1978.

------La evolución económica de Colombia 1830-1900. Manual de historia de Colombia, Tomo II. Colcultura, Bogotá, 1978.

MINISTERIO de Educación Nacional. Educación Colombiana. Imprenta Nacional, Bogotá, 1959.

MESA, Darío. Treinta Años de Historia en Colombia. Trabajo Publicado en ensayos sobre historia política contemporánea. Bogotá, Editorial La Pulga, 1977.

MOLINA, Gerardo. Las Ideas Liberales en Colombia. Tomo II y III. Editorial Tercer Mundo. Bogotá, 1978.

NIETO Caballero, Agustín. Sobre el Problema de la Educación Nacional. Selección Samper Ortega de Literatura Colombiana Sección 5 No. 30. Editorial Minerva, Bogotá, 1937.

PALACIO, Marco. El Café (1850-1970) Una historia Económica, Social y Política. Editorial Presencia, Bogotá, 1979.

POVEDA, Ramos, Rafael. Historia de la Industria en Colombia. Revista Trimestral de la Andi No. 11, Octubre de 1970, Medellín, 1970. 
RIPPY, Fred. El capital norteamericano y la penetración imperialista en Colombia. Editorial La Oveja Negra, Medellín, 1970.

URRUTIA, Miguel. El desarrollo del movimiento sindical y la situación de la clase obrera. Ensayo publicado en Manual de Historia de Colombia. Tomo III, Colcultura, Bogotá, 1980. 